\title{
A propósito da causa
}

\author{
Maria Eliza Giusti \\ Universidade Federal do Paraná
}

\begin{abstract}
Resumo
O presente artigo pretende tecer algumas articulações sobre o conceito de causa em Psicanálise. Também estabelece um paralelo com esse conceito na ciência psicológica, em especial o behaviorismo. Ainda, faz o mesmo paralelo com o conceito do eu e do sujeito do inconsciente. O sentido do trabalho é investigar as relações entre o saber e a verdade.

Palavras-chave: a causalidade; discurso analítico; a descoberta freudiana.
\end{abstract}

\begin{abstract}
The cause

The present article presents a discussion about the. It also shows a parallel with such concept in the science of psychology, particularly with behaviorism. Another parallel with the concepts of self and of subject of the unconscious is also presented. The aim of the work is to investigate the relation between knowledge and truth.

Keywords: cause in Psychoanalysis, knowledge and truth
\end{abstract}

O que descobrimos na análise está no nível da ortodoxa. Tudo o que se opera no campo da ação analítica é anterior à constituição do saber, o que não impede que, operando neste campo, tenhamos constituído um saber,

e que se mostrou inclusive excepcionalmente eficaz, como é natural, já que toda ciência surge de um manejo da linguagem que é anterior à sua constituição, e que é neste manejo que se desenvolve a ação analítica

(Lacan, 1985, p. 30).

Este trabalho pretende interrogar este parágrafo, escrito por Lacan, no Seminário 2, nos seguintes pontos:

$$
\begin{aligned}
& 1 \text { - O que é anterior ao saber? } \\
& 2 \text { - O que é o saber? } \\
& 3 \text { - Ao que estas perguntas nos conduzem? }
\end{aligned}
$$

\section{O aquém do saber}

No capítulo "Saber, Verdade, Opinião", onde a frase acima é encontrada, há a referência ao diálogo 'Mênon', de Platão, no qual com a questão da virtude a postos, a ortodoxa e o saber são definidos. A ortodoxa, ou opinião certa é aquela que contém a verdade sem o saber. Assim, "bem administrar a casa (economia) e os Estados (política), era a fórmula que resumia, ao tempo de Sócrates, a virtude ou virtude política" (Costa, s.d., p. 66). O problema a seguir é de como ensiná-la. No diálogo, depois de acordado que não é possível ensinar a virtude, portanto, isto quer dizer que ela está no campo da ortodoxa; o seu estatuto, então, é que é questionado, visto que não sendo possível sua amarração em um saber constituído e passível de ser transmitido, sua relação é com a divindade e a verdade. Por conseguinte, a virtude não pode ser ensinada, ela é dada à maneira de uma opinião certa.

Já o saber guarda sua relação com a ciência e o ensino, é obra racional.

Conseqüentemente há aqui uma disjunção entre verdade e saber. Pois bem, o que está no aquém do saber, é uma verdade que pode ser apreendida pela opinião certa, que diz respeito a um campo da experiência humana que o saber não recobre. Há um enigma aí.

\section{O saber}

Seguindo Lacan, a epistemé, o saber ligado por uma ocorrência formal, é dada pela ordem simbólica, estruturada pela linguagem. Portanto, a função simbólica introduz um campo universal de onde o saber vai se constituir. Em últimas, o saber é a articulação simbólica sobre alguma coisa. E uma vez dado é como se sempre estivesse aí.

O universal é distinto da generalidade porque, nesta, o que está em jogo é a simples difusão, o que equivale a dizer, está por todo lado. Não obstante, 
definir o campo simbólico como universal é dizer que, não importa onde esteja, onde está, está de uma forma fixa. Há uma lei que lhe é própria, a partir da qual toda uma série de conseqüências pode se desenvolver. É o mesmo princípio do funcionamento de uma máquina.

A ciência põe a razão a trabalhar para produzir um saber, amarrado, articulado na ordem simbólica; porém, seu preço, é a impotência. Há um pedaço inassimilável, o campo da verdade não é recoberto.

No dizer de Bachelard, a impossibilidade da ciência é de conhecer a essência do espírito, a essência da matéria, o problema da morte.

\section{A descoberta freudiana}

Lacan dá o mesmo estatuto da descoberta copernicana à descoberta freudiana, isto é, a de um saber com o poder de descentralização, de tirar dos eixos. Se o centro do universo não é a Terra, se o centro da Terra não é o homem, o centro do homem não é a razão.

Com Sócrates, aprende-se que se a virtude faz questão, o que se apreende é um saber, que para tanto basta uma boa articulação. A coisa mesma, objeto desse saber, cai por terra.

Com Descartes, após o período obscurantista da Idade Média - com a cristalização da verdade divina e o saber na fé - a razão pode adquirir autonomia através da res cogitans. O eu pensa, logo existe. Logo, há um eu. É um juízo de existência. Porém, só pode ser apreendido pelo método da dúvida. Quem é o eu? Não se sabe.

"Mesmo que efetivamente seja verdade que a consciência é transparente a si própria e que é apreendida como tal, fica patente que, nem por isso, o eu lhe é transparente. Ele não lhe é dado de um modo diferente do de um objeto" (Lacan, 1985, p. 13).

A Psicologia nasce com o propósito de fazer ciência do eu. Há a psicofisiologia do eu, transformando-o em sensações, percepções. Na esteira da cientificidade, nasce o Behaviorismo. A grande pergunta inicial é: por que as pessoas se comportam de uma certa maneira?

A pergunta pela causa conduz a uma construção do objeto a ser tratado. Por que, seguindo o raciocínio de Skinner, as causas que determinam tal comportamento podem ser encontradas nos sentimentos e estados mentais, porém onde são encontrados, de que material são feitos? Se constituem-se em um fato mental, como pode um fato mental causar um fato físico?

Pelo progresso no pensamento científico, essa charada teve respostas distintas. Numa primeira fase, a busca pela causa foi abandonada, e a estratégia consistiu em descrever o que as pessoas faziam. $\mathrm{O}$ método era da observação direta, com auxílio de entrevistas, questionários e testes. Essa fase, na história, era denominada 'Estruturalismo'. O resultado foi a descrição do comportamento, deixando em aberto aos mentalistas a questão da causa.

Num segundo movimento dessa história, adveio o Behaviorismo Metodológico, circunscrevendo a causa aos acontecimentos físicos anteriores ao comportamento. Assim, a previsão e controle eram possíveis, uma vez que se estudasse a história antecedente de determinado comportamento. Isto originou um novo progresso na observação científica do que era o comportamento e nas causas genéticas e ambientais, desvinculando o mentalismo da operação.

Muito embora, por mais que as sensações ou percepções fossem postas como operação de discriminação e assim passíveis de serem estudadas; e isto seria uma parte do mundo interno do humano, como resolver a outra parte, os fluxos de consciência?

O terceiro passo foi a consolidação do objeto a ser estudado, o comportamento, definido pelo Behaviorismo Radical.

Se a fase anterior consistia em estudar somente o que fosse possível construir objetivamente sobre os acontecimentos privados, esta nova fase consiste em: "O que é sentido ou introspectivamente observado não é nenhum mundo imaterial da consciência, da mente ou da vida mental, mas o próprio corpo do observador. Um organismo comporta-se de determinada maneira devido à sua estrutura atual, mas a maior parte disso está fora do alcance da introspecção. De momento, devemos contentar-nos, como insiste o behaviorista metodológico, com a história genética e ambiental da pessoa" (Skinner, 1982, p. 19).

As causas então, para o agir, ficam circunscritas nas contingências de sobrevivência e de reforço, nas quais se combinem a história genética e ambiental; o comportamento é a definição do agir.

Há o agir presente, com o comportamento usual; há o agir futuro, com a descrição do ato de perceber; há o comportamento passado e o comportamento encoberto, que é o pensar. Pronto, o objeto dessa ciência está definitivamente construído. Os sentimentos também recebem uma definição em relação a comportamentos, tais como estados de privação ou estimulação adversativa. Idéia, vontade, propósito ou intenção são definidos como comportamentos encobertos ou prováveis.

Assim, "Numa análise comportamental, uma pessoa é um organismo, um membro da espécie humana que adquiriu um repertório de comportamentos. Ela continua sendo um organismo para o anatomista e para o fisiologista, mas é uma 
pessoa para aqueles que lhe dão importância ao comportamento" (Skinner, 1982, p. 145).

O Eu não é um agente, é equivalente a um lugar comportamental, um ponto ao qual confluem condições genéticas e ambientais num efeito comum.

Esse Eu comportamental pode se conhecer através da comunidade verbal. $\mathrm{O}$ autoconhecimento tem origem social; a partir de sua demanda, teorias são produzidas. Mas fica um hiato, há contingências próprias que não são explicadas. A isso Skinner propõe a análise experimental para compreender-se a si mesmo num sentido científico ou tecnológico.

A lei da ciência, no Behaviorismo Radical, fica circunscrita à descrição das contingências que prevalecem no meio independentemente de qualquer ação humana deliberada. No que tange ao comportamento, o sentido da palavra 'lei' fica desdobrado por regra, por sua vez embutida nas contingências de reforço. Resumindo, um comportamento é produzido porque é desencadeado a partir de uma contingência de reforço. O efeito, o reforço, é gerador de novo comportamento.

Para explicar, por fim, o que vem a ser causa, Skinner põe no lugar o conceito de razões. As razões de um comportamento são explicadas pelas suas conseqüências.

O raciocínio, por sua vez, é definido pelo método indutivo e dedutivo. Tanto o raciocínio para a vida cotidiana quanto para a ciência.

A verdade é assim exposta:

"A verdade de uma afirmação de fato está limitada pelas fontes do comportamento do falante (...). Não há maneira de uma descrição verbal de um cenário poder ser absolutamente verdadeira. Uma lei científica é possivelmente derivada de muitos episódios desse tipo, mas é igualmente limitada pelo repertório dos cientistas envolvidos ...). Nenhuma dedução de uma regra ou lei pode, por isso, ser absolutamente verdadeira. Se houver uma verdade absoluta, ela só pode ser encontrada em regras derivadas de regras, e isto é mera tautologia (Skinner, 1982, p. 118).

Retornamos ao ponto inicial, o enigma da verdade.

A descoberta freudiana foi, então, descentralizadora. Tirou do lugar, e ao mesmo tempo colocou a instância do Eu.

A primazia do Eu penso foi descentrada por Freud com o conceito do sujeito do inconsciente. No entanto, é certo que o eu pensa posto que ingressou na ordem simbólica.

Essa dobradiça tem como elemento nodal a linguagem, porque o humano é constituído por ela, por isso adquire a substancialidade de ser pensante; e, por definição, o inconsciente é estruturado como uma linguagem.
A linguagem que convém aqui denotar é, pela referência lacaniana, a de Santo Agostinho. Aquela que tem, em primeiro plano, a dissociação entre a palavra e a coisa a que ela designa, e em segundo, a sua emergência para designar a relação da linguagem com a alma.

"Será que não existe certa reação da alma quando, não vendo uma coisa, se dá conta, entretanto, ou acredita ter-se dado conta de que essa coisa não existe? Por que não dizer que tal é o objeto significado pela palavra nada, mais do que a coisa mesma, que não existe?" (Lacan, 1979, p. 286).

Esta é a longa pergunta-resposta de Agostinho ao embaraçado Adeodato quando constata a radical separação entre a coisa e a palavra e se pergunta por que falar então? Ao que arremata com a seguinte conclusão: "Portanto, o que é significado aqui é a reação da alma diante de uma ausência de algo que poderia estar lá" (Lacan, 1979, p. 286).

A presença na ausência, eis a articulação simbólica. Pois que Agostinho diz que a alma reage ao nada produzindo uma palavra. Esta palavra nomeia, não a coisa mesma, mas a expressão da alma. Onde está a palavra, logicamente, não está a coisa mesma que ela nomeia.

O sujeito do inconsciente é constituído pelo Outro, é efeito da linguagem, posto que um significante representa um sujeito. É o movimento de alienação e entrada na ordem simbólica, na qual há a lei que determina a cadeia dessa dimensão. A lei da linguagem põe em pauta um destino, um modo de operar.

O sujeito, apenso ao simbólico, produz um saber, regulado pelo funcionamento automático do princípio do prazer, movimento definido como o automaton.

Porém, há uma falta que é de estrutura, o significante não contém o significado; se apresenta um sujeito, tão somente o lança na dúvida, pois que só se remete para outro significante. Um significante representa um sujeito para outro significante. Ao invés do significado, o que se pode obter é uma metáfora, apenas.

Mas, voltando ao nada do início, o real, como apreendê-lo, então?

Há a insuficiência do significante para representar o real, no entanto ele está lá. Onde?

O universo simbólico já está no mundo antes do sujeito, fora dele; com o movimento de identificação, o sujeito faz a entrada neste universo e o faz seu, o põe para dentro.

Se há uma inversão, no real também pode haver. Com efeito, o que resta sempre inassimilável, sempre inapreensível, o que comanda mesmo a repetição, é a 
tiquê. O encontro com a falta sempre repetida, produzida como que por acaso.

Lacan, no Seminário 11, diz que uma falta recobre a outra. "É uma falta engendrada pelo tempo precedente que serve para responder à falta suscitada pelo tempo seguinte" (Lacan, 1979, p. 203).

Há duas faltas. Há a falta no Outro, no universo simbólico; e, há a falta no sujeito. Por ser sexuado, há uma parte de vida imortal, que o sujeito perde ao nascer. Ele nasce para morrer.

O encontro com o real, então, sempre repetido, porque sempre inominado pelo significante, é o que se apresenta do sujeito como se fôra fora dele. Não há como escapar da repetição, ela sempre estará no horizonte, é de estrutura. Visto que não se pode abolir o real. Ele se imporá, mesmo que por acaso.

Uma falta recobre a outra. A falta simbólica traz de volta a falta real.

A dimensão da causalidade na Psicanálise existe a partir de duas faltas. São estas as causas do que funda, faz nascer um sujeito, produzido por identificações exteriores a ele.

Uma vertente, a simbólica, a metáfora é a produção da identificação significante. Na vertente real, a falta no Outro faz intervir o desejo, e pelo movimento metonímico, o sujeito vai buscar o que anima esse desejo do Outro, propondo-se como objeto mesmo desse desejo, produzindo um outro tipo de identificação. Ele será esse objeto. Assim, podemos entender quando Lacan conclui que o Eu é um outro.

$\mathrm{O}$ significante e o objeto são as duas vias de causação do sujeito, no que se imprimem pela falta, pela ausência. Eles presentificam a falta.

As produções inconscientes surgem para recobrir a falta que é de estrutura, uma vez que é traumática. O sintoma, uma produção do inconsciente, é o justo movimento de substituição significante. Faz desaparecer o significante traumático por um outro, é uma metáfora.

$\mathrm{O}$ que causa o sintoma não é senão o entrecruzamento de duas faltas, a saber, o encontro atual, como que por acaso, de uma resignificação de um passado. A resignificação, o plano simbólico, traz a falta do significante - a barra no Outro. E traz a falta do objeto - a barra no Sujeito.

Freud e Lacan utilizam-se de um sonho a título de ilustração. Um pai sonha com seu filho de pé ao lado de seu leito. O filho apanha-o pelo braço e sussurralhe em tom de censura: 'pai, não vê que estou queimando?' Em seguida há o despertar. Já sabemos que na peça contígua há o funeral do filho e o crepitar de chamas incendiando o caixão. A interpretação põe peso, para o despertar, não na realidade percebida pelo barulhinho, mas na realidade da mensagem 'Pai, não vê que estou queimando?' É uma frase forte por si só para acordar um pai. Um pai que se encontra diante de um vazio de significação do significante pai e seus deveres, e de um vazio absoluto diante da morte.

\section{Conclusão}

A ortodoxa, o dizer a verdade em seu estado nascente, é elidida pela ciência, pois a lei que a comanda é da articulação significante, um saber, um dito. Um saber que é impotente sobre a verdade, sobre a causa.

A virtude, o agir bem, só pode ser explicada a partir do que é a verdade dessa ação. Em Sócrates, encontramos a verdade na divindade; como de resto na Filosofia, ela está alhures.

$\mathrm{Na}$ Psicanálise, encontramos a verdade no lugar da causa. A verdade do sujeito é a articulação significante do que o causa. É o que faz a junção da lei e do desejo. Mais uma descentralização efetua-se assim, ali onde era a verdade na divindade (aquela de Sócrates e depois de Descartes), estará, desta vez, a verdade do sujeito. Agora sim, ele foi colocado no centro. No centro da fogueira da sua verdade.

Em síntese, a causa tem sua definição por um efeito. Em função de um encontro entre o sujeito e o Outro, o efeito de linguagem e efeito de fala causam. A causa advém de um efeito na relação do sujeito ao Outro.

Finalmente, a apreensão da verdade pelo saber coloca, sobretudo, a Psicanálise como um sintoma. Um sintoma necessário. Por quê? Ora, Lacan diz - no início deste trabalho - que tudo o que se desenvolve no campo da ação analítica está no nível da ortodoxa; isto é, o saber-fazer; porém o que se obtém como efeito desta operação - o discurso analítico - é a colocação do saber no campo da verdade. Certamente com uma ressalva: é impossível o saber todo. É impossível abarcar a verdade toda pelo todo-saber. A falta é de estrutura.

\section{Referências}

Bachelard, G. (s.d.). A epistemologia. São Paulo: Martins Fontes.

Costa, J. C. (s.d.). Nota do revisor. Em Platão, Diálogos (p. 66). São Paulo: Ediouro.

Lacan, J. (1979). Seminário1: Os escritos técnicos de Freud. Rio de Janeiro: Zahar.

Lacan, J. (1979). Seminário 11: Os quatro conceitos fundamentais da psicanálise. Rio de Janeiro: Zahar.

Lacan, J. (1985). Seminário 2: O eu na teoria de Freud e na técnica da psicanálise. Rio de Janeiro: Zahar.

Skinner, B. F. (1982). Sobre o Behaviorismo. São Paulo: Cultrix. 
Revisado: 15/06/2002

Aceito em 26/06/2002 


\section{Sobre a autora}

Maria Eliza Giusti: Professora do Departamento de Psicologia da UFPR; Mestre em Psicologia Clínica pela PUCSP; Doutoranda em Psicologia Clínica pela PUC-SP. E-mail: melizag@ bol.com.br. 